\title{
Corrigendum: The immune synapse clears and excludes molecules above a size threshold
}

Adam N.R. Cartwright, Jeremy Griggs \& Daniel M. Davis

Nature Communications 5:5479 doi: 10.1038/ncomms6479 (2014); Published 19 Nov 2014; Updated 6 Mar 2015

This Article contains an error in Fig. 6d, such that the 'LDL' data set is not visible. The correct version of this figure follows.
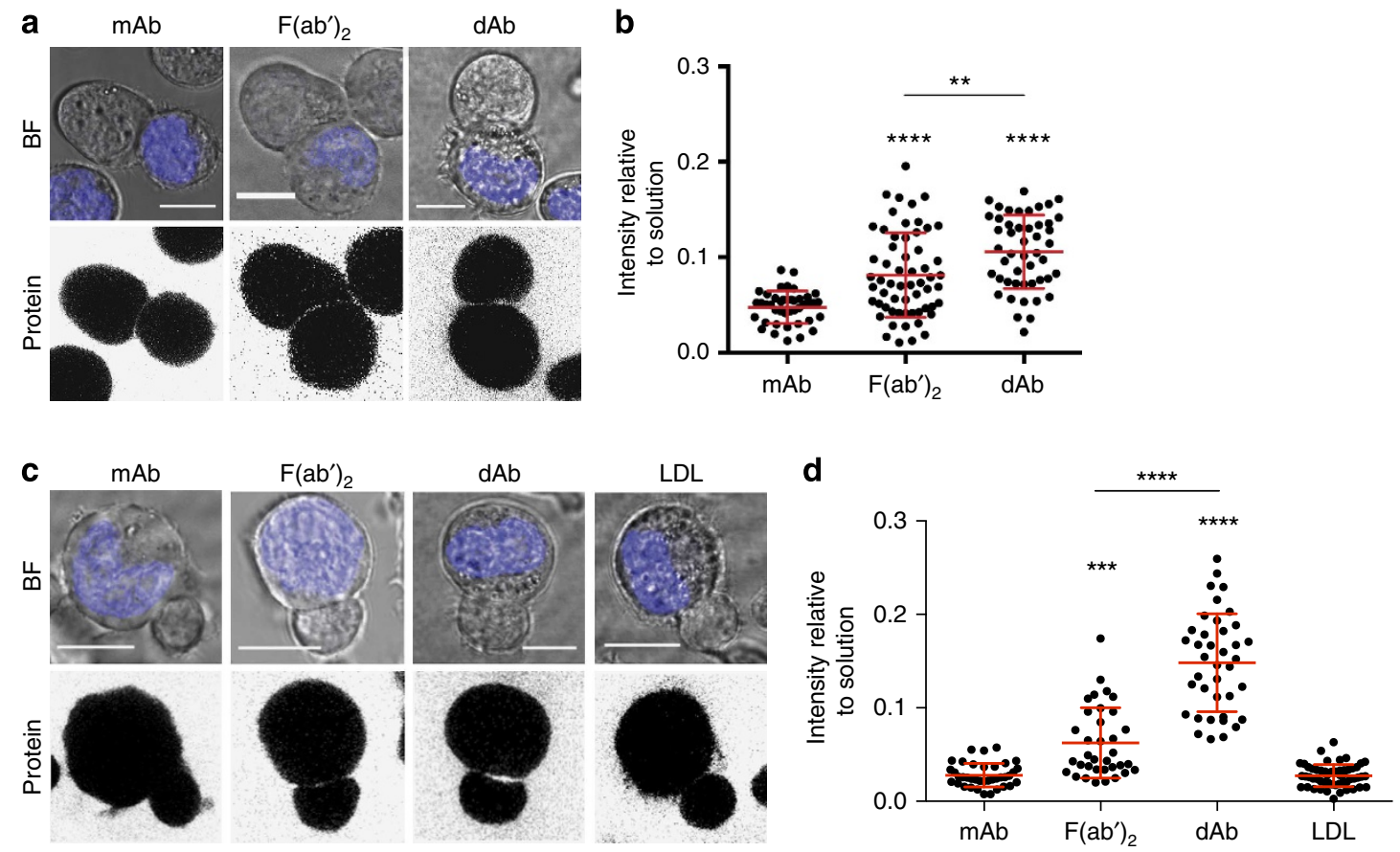

Figure 6 